\title{
PENGUKURAN TOTAL DISSOLVED SOLID (TDS) DALAM FITOREMEDIASI DETERJEN DENGAN TUMBUHAN Sagittaria lancifolia
}

\section{Total Dissolved Solid (TDS) Measurement in Phytoremediation of Detergent by Sagittaria lancifolia Plant}

\author{
Elisa Kustiyaningsih ${ }^{1 *}$, Rony Irawanto ${ }^{2}$ \\ ${ }^{1}$ Program Studi Biologi, Jurusan Biologi, Fakultas Matematika dan Ilmu Pengetahuan Alam Universitas \\ Negeri Surabaya. \\ 2Program Doktor Ilmu Lingkungan, Pascasarajana Universitas Brawijaya. \\ *Penulis korespondensi: elisakustiyaningsih@yahoo.co.id
}

\begin{abstract}
As the population increases, the need for detergent will increase. This study aimed to determine the value of TDS in detergent solution at different concentrations and detention times. This study was an experimental study using a randomized block design with three treatment factors. The treatments included phytoremediation (presence or absence of plants), detergent concentrations used were 10, 50, and $75 \mathrm{ppm}$, and detention times were 7 and 14 days, each with three replications. The tool used was the TDS Meter. The data obtained in the form of TDS values were further analyzed descriptively and presented in the form of tables, graphs and descriptive analysis. The results showed that the TDS values fluctuated every day. The lowest average TDS value was found in phytoremediation treatment with a concentration of $10 \mathrm{ppm}$ with a detention time of 7 days which was $174 \mathrm{mg} \mathrm{L}^{-1}$, while the highest average TDS value was found in phytoremediation treatment with a concentration of $75 \mathrm{ppm}$ with a detention time of $14 \mathrm{mg}$ of $237 \mathrm{mg} \mathrm{L}^{-1}$. The higher the concentration of detergent and the longer the detention time in the phytoremediation treatment, the higher the average TDS value.
\end{abstract}

Keywords: detergent solution, phytoremediation, Sagittatria lancifolia, TDS

\section{Pendahuluan}

Pemakaian deterjen meningkat setiap tahun. Pertambahan penduduk dengan segala aktivitasnya yang sedemikian pesat telah mengakibatkan peningkatan jumlah limbah yang dibuang ke perairan. Produksi limbah deterjen yang semakin tinggi, dipacu dengan adanya kegiatan masyarakat yang beraneka ragam, menyebabkan terakumulasinya limbah di perairan. Masyarakat cenderung menggunakan deterjen untuk mencuci dengan takaran yang dibuat sendiri, tanpa melihat takaran yang sudah sesuai pada kemasannya. Penggunaan yang tidak sesuai akan menyebabkan kadar TDS yang tinggi, begitupula jika dibuang ke perairan tanpa proses pengolahan terleih dahulu. Total Dissolved
Solid (TDS) atau padatan terlarut adalah padatan-padatan yang mempunyai ukuran lebih kecil dari padatan tersuspensi. Bahan-bahan terlarut pada perairan alami tidak bersifat toksik, akan tetapi jika berlebihan dapat meningkatkan nilai kekeruhan yang selanjutnya akan menghambat penetrasi cahaya matahari ke dalam air dan akhirnya berpengaruh terhadap proses fotosintesis diperairan. Tingginya kadar TDS apabila tidak dikelola dan diolah dapat mencemari badan air. Selain itu juga dapat mematikan kehidupan aquatik, dan memiliki efek samping yang kurang baik pada kesehatan manusia karena mengandung bahan kimia dengan konsentrasi yang tinggi antara lain fosfat, surfaktan, ammonia, dan nitrogen serta kadar padatan tersuspensi maupun terlarut, 


\section{Jurnal Tanah dan Sumberdaya Lahan Vol 7 No 1 : 143-148, 2020 \\ e-ISSN:2549-9793, doi: 10.21776/ub.jts1.2020.007.1.18}

kekeruhan, BOD5, dan COD yang tinggi (Ahmad dan El-Dessouky, 2008). Adapun upaya untuk menanggulangi pencemaran yang timbul akibat deterjen adalah dengan fitoremediasi. Penggunaan tumbuhan air merupakan salah satu pengolahan untuk menurunkan kadar bahan organik detergen di perairan. Tumbuhan yang digunakan sebagai agen fitoremediasi ialah tumbuhan yang memiliki kemampuan untuk mengangkut berbagai zat toksik yang ada. Beberapa tumbuhan yang bisa dijadikan sebagai fitoremediator dalam upaya mengatasi pencemaran air salah satunya yaitu tumbuhan Daun Tombak (Sagittaria lancifolia) (Irawanto, 2016). Tumbuhan ini merupakan tumbuhan air yang banyak dijumpai di Kebun Raya Purwodadi. Pada penelitian Baroroh dan Irawanto (2016), mengungkapkan bahwa tumbuhan Sagittaria lancifolia memiliki kandungan air kurang dari 90\%. Maka dari itu, tumbuhan akuatik tersebut akan sangat efektif apabila dijadikan sebagai sampel pengujian tumbuhan untuk fitoremediasi. Oleh karena itu, penelitian ini bertujuan untuk mengetahui nilai TDS dalam larutan deterjen pada berbagai konsentrasi dan waktu detensi yang berbeda.

\section{Bahan dan Metode}

\section{Tempat dan waktu penelitian}

Penelitian ini merupakan penelitian eksperimental metode RAK (Rancangan Acak Kelompok) dikarenakan kondisi faktor fisik/lingkungan yang relatif heterogen. Terdapat tiga faktor perlakuan yaitu fitoremediasi, konsentrasi dan waktu detensi, dengan 3 kali ulangan. Penelitian ini dilakukan pada bulan Februari - Mei 2019 di Rumah Kaca Kebun Raya Purwodadi.

\section{Bahan dan alat}

Bahan yang digunakan dalam penelitian ini adalah tumbuhan Sagittatria lancifolia dan larutan deterjen. Alat yang digunakan meliputi toples (kapasitas 5 liter, diameter $23 \mathrm{~cm}$, dan tinggi 20 $\mathrm{cm}$ ), gelas ukur $500 \mathrm{ml}$ dan $1000 \mathrm{ml}$, gunting stek, cetok, sabit dan TDS meter.

\section{Alur penelitian}

Aklimatisasi bertujuan untuk mengadaptasi tumbuhan Sagittaria lancifolia terhadap lingkungan yang baru. Pengambilan sampel tumbuhan dipilih dengan ciri-ciri daun berwarna hijau segar tidak mengalami klorosis dan nekrosis, jumlah daun 3-4 helai. Sampel yang telah didapat kemudian diaklimatisasi pada $4 \mathrm{~L}$ media air suling selama 14 hari. Tumbuhan yang sudah diaklimatisasi selanjutnya dicuci hingga bersih dan siap untuk ditanam di media tanam air larutan deterjen. Pembuatan media tanam dilakukan dengan menyiapkan larutan deterjen dengan konsentrasi 10 ppm, 50 ppm dan 75 ppm. Total volume media tanam untuk masingmasing unit perlakuan sebanyak 4 L. Pembuatan konsentrasi larutan deterjen yaitu 10 ppm: tumbuhan Sagittaria lancifolia dengan 0,04 gram detergen dalam $4 \mathrm{~L}$ air. 50 ppm: tumbuhan Sagittaria lancifolia dengan 0,2 gram detergen dalam 4 L air. 75 ppm: tumbuhan Sagittaria lancifolia dengan 0,3 gram detergen dalam $4 \mathrm{~L}$ air. Tahap perlakuan yaitu pemaparan tumbuhan dalam larutan deterjen. Tumbuhan yang telah diaklimatisasi, kemudian dimasukkan dalam toples yang telah berisi larutan deterjen dengan berbagai konsentrasi yang telah ditentukan. Tahap pengambilan data yaitu pengukuran TDS pada media tanam menggunakan TDS meter. Pengukuran TDS dilakukan selama waktu detensi yang telah ditentukan yaitu 7 dan 14 hari.

\section{Pengumpulan data}

Data yang diperoleh berupa data primer, yang akan disajikan dalam bentuk tabel dan grafik. Kemudian dilakukan pembahasan dengan mengevaluasi, menguraikan dan menyelidiki hasil yang telah diperoleh dengan membandingkan penelitian terdahulu.

\section{Analisis data}

Analisis data dilakukan secara deskriptif kualitatif yaitu cara analisis yang menguraikan fakta-fakta atau data secara berurutan dengan membandingkan perlakuan 1 (kontrol/ tanpa tanaman) dan perlakuan 2 (ada tanaman).

\section{Hasil dan Pembahasan}

Larutan deterjen merupakan air deterjen sintetis yang digunakan masyarakat untuk mencuci. Penelitian ini dilakukan dengan proses fitoremediasi agar kualitas airnya menjadi lebih baik. Penelitian dilakukan dengan menggunakan tumbuhan Sagittaria lancifolia yang dipaparkan 
dalam media tanam yang mengandung larutan deterjen pada konsentrasi dan waktu detensi yang berbeda. Parameter yang diukur adalah TDS. Nilai TDS ditunjukkan pada tabel berikut (Tabel 1). Berdasarkan Tabel 1, rerata hasil TDS pada media tanam larutan deterjen adalah sebagai berikut: rerata nilai TDS kontrol (tanpa tumbuhan) pada konsentrasi 10 ppm, 50 ppm dan 75 ppm dan waktu detensi 7 hari berturutturut yaitu $178 \mathrm{mg} \mathrm{L}^{-1}, 190 \mathrm{mg} \mathrm{L}^{-1}$ dan $201 \mathrm{mg}$ $\mathrm{L}^{-1}$. Perlakuan dengan tumbuhan Sagittaria lancifolia menunjukkan perubahan nilai TDS berturut-turut sebesar $174 \mathrm{mg} \mathrm{L}^{-1}, 192 \mathrm{mg} \mathrm{L}-1$ dan $206 \mathrm{mg} \mathrm{L}^{-1}$. Proses fitoremediasi mengakibatkan penurunan nilai TDS pada media tanam. Penurunan nilai TDS terjadi pada perlakuan fitoremediasi konsentrasi 10 ppm. Hal ini diduga karena berkurangnya jumlah senyawa organik pada media tanam. Semakin tinggi konsentrasi deterjen maka semakin tinggi pula nilai TDS pada media tanam. Perlakuan antara fitoremediasi, konsentrasi dan waktu detensi terhadap nilai TDS pada media tanam dapat dilihat pada Gambar 1.

Tabel 1. Rerata TDS pada berbagai konsentrasi deterjen dan waktu detensi 7 hari.

\begin{tabular}{|c|c|c|c|c|c|c|}
\hline \multirow[t]{2}{*}{ Hari ke- } & \multicolumn{3}{|c|}{ Kontrol (tanpa tumbuhan) $\mathrm{mg} \mathrm{L}^{-1}$} & \multicolumn{3}{|c|}{ Perlakuan (ada tumbuhan) $\mathrm{mg} \mathrm{L}^{-1}$} \\
\hline & $10 \mathrm{ppm}$ & $50 \mathrm{ppm}$ & $75 \mathrm{ppm}$ & $10 \mathrm{ppm}$ & $50 \mathrm{ppm}$ & $75 \mathrm{ppm}$ \\
\hline 1 & 183 & 188 & 210 & 168 & 191 & 198 \\
\hline 2 & 173 & 190 & 202 & 178 & 201 & 222 \\
\hline 3 & 165 & 188 & 197 & 170 & 193 & 215 \\
\hline 4 & 164 & 193 & 195 & 173 & 187 & 197 \\
\hline 5 & 184 & 187 & 199 & 170 & 187 & 200 \\
\hline 6 & 186 & 192 & 204 & 173 & 190 & 203 \\
\hline 7 & 191 & 194 & 203 & 182 & 198 & 210 \\
\hline Rata-rata & 178 & 190 & 201 & 174 & 192 & 206 \\
\hline
\end{tabular}

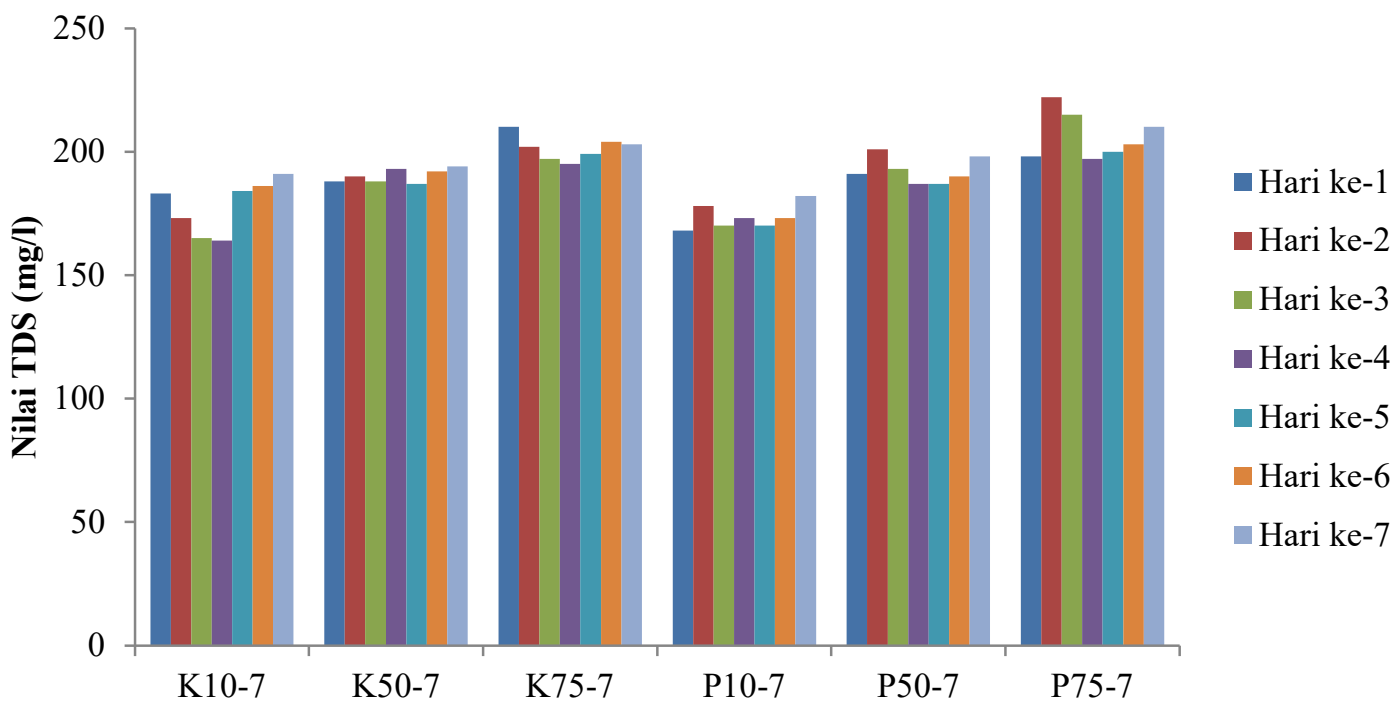

Gambar 1. Rerata TDS pada berbagai konsentrasi deterjen dan waktu detensi 7 hari.

K10-7: kontrol, 10 ppm, 7 hari K50-7: kontrol, 50 ppm, 7 hari K75-7: kontrol, 75 ppm, 7 hari
Keterangan:

P10-7: perlakuan, $10 \mathrm{ppm}, 7$ hari P50-7: perlakuan, $50 \mathrm{ppm}, 7$ hari P75-7: perlakuan, 75 ppm, 7 hari 


\section{Jurnal Tanah dan Sumberdaya Lahan Vol 7 No 1 : 143-148, 2020 \\ e-ISSN:2549-9793, doi: 10.21776/ub.jts1.2020.007.1.18}

Gambar 1 memperlihatkan rerata nilai TDS yang fluktuatif setiap harinya, selama 7 hari. Setelah dilakuan fitoremediasi, rerata nilai TDS mengalami penurunan. Penurunan tersebut merupakan perlakuan terbaik yang ditunjukkan pada fitoremediasi (ada tumbuhan) konsentrasi $10 \mathrm{ppm}$ dan waktu detensi 7 hari. Pada penelitian Sari et al. (2017), menyebutkan bahwa perlakuan kayu apu dan azolla mampu menurunkan nilai TDS. Nilai TDS air irigasi di Subak Sembung sebelum diberikan perlakuaan sebesar $270 \mathrm{mg} \mathrm{L} \mathrm{L}^{-1}$. Setelah pemberian perlakuan kayu apu pada waktu 5 minggu nilai TDS-nya sebesar $80 \mathrm{mg} \mathrm{L}^{-1}$ dan perlakuan dengan tanaman azola juga menunjukkan perubahan TDS pada waktu 5 minggu sebesar $20 \mathrm{mg} \mathrm{L}^{-1}$.

Penurunan TDS terjadi pada pengamatan 5 minggu untuk semua perlakuaan. Hal ini juga sesuai dengan penelitian Prasetyo et al. (2013), yang menjelaskan bahwa dengan penanaman vegetasi riparian sepanjang minimal $125 \mathrm{~m}$ selama 50 hari di saluran irigasi sudah mampu menurunkan kadar TDS secara signifikan. Penurunan ini menunjukkan bahwa vegetasi riparian sangat berperan dalam peningkatan kualitas air irigasi. Total senyawa organik dan non organik yang berasal dari polutan dapat direduksi oleh vegetasi riparian. Vegetasi riparian mampu mereduksi residu berbahaya dari pestisida dan senyawa lainnya ( $\mathrm{Li}$ et al., 2008). Pada penelitian Safitri et al. (2019) menyebutkan bahwa hasil pengukuran TDS pada air limbah laundry mengalami penurunan setelah perlakuan selama 14 hari dengan menggunakan $L$. minor dan $H$. verticillata. Pengukuran TDS air limbah laundry sebelum perlakuan (hari ke-0) sebesar $796 \mathrm{mg} \mathrm{L}^{-1}$ setelah perlakuan selama 14 hari TDS menurun berkisar antara 764 - 779,33 $\mathrm{mg} \mathrm{L}^{-1}$ dengan rentang persentase penurunan $2,09 \%-4,02 \%$.

Pada penelitian Febrianda et al. (2018) juga menyebutkan bahwa efektivitas penggunaan biofilter dengan proses anaerob, aerob, eceng gondok (E. crassipes) efektif dalam menurunkan kadar TDS pada limbah cair laundry dengan persentase penurunan sebesar 82,18\%. Akar tumbuhan berperan penting dalam menyerap TDS dalam proses fitoremediasi. Menurut Sudiro dan Agnes (2013), H. verticillata selain memanfaatkan akar, juga memanfaatkan daun dan batangnya yang ikut terendam dalam air limbah untuk menyerap TSS dan TDS, sementara $L$. minor hanya memanfaatkan akarnya. Pada tumbuhan Sagittaria lancifolia, hanya memanfaatkan akarnya saja. Akar tumbuhan Sagittaria lancifolia yang lebat berperan sebagai tempat mikroorganisme berkembang biak sehingga aktivitas perombakan mikroorganisme pun juga tinggi dalam menurunkan TDS. Proses penurunan TDS memanfaatkan aktivitas mikroorganisme dalam media tanam. Adanya mikroorganisme yang melakukan penguraian padatan organik berupa minyak, lemak dan anorganik berupa bahanbahan kimia yang terkandung dalam deterjen seperti surfaktan, zat builder, zat filler dan zat additive lain yang ada pada media tanam sehingga mereduksi padatan terlarut. Suriawira (2005), menyatakan mikroorganisme pada akar tumbuhan mampu menguraikan bahan-bahan organik maupun bahan anorganik menjadi senyawa-senyawa yang lebih sederhana, sehingga akar lebih mudah menyerap bahanbahan tersebut.

Berdasarkan Tabel 2, rerata hasil TDS pada media tanam larutan deterjen adalah sebagai berikut: rerata nilai TDS kontrol (tanpa tumbuhan) pada konsentrasi $10 \mathrm{ppm}, 50 \mathrm{ppm}$ dan 75 ppm dan waktu detensi 14 hari berturutturut yaitu $175 \mathrm{mg} \mathrm{L}^{-1}, 196 \mathrm{mg} \mathrm{L}^{-1}$ dan $204 \mathrm{mg}$ $\mathrm{L}^{-1}$. Perlakuan dengan tumbuhan Sagittaria lancifolia menunjukkan perubahan nilai TDS berturut-turut sebesar $185 \mathrm{mg} \mathrm{L}^{-1}, 208 \mathrm{mg} \mathrm{L}^{-1}$ dan $237 \mathrm{mg} \mathrm{L}^{-1}$. Hasil tersebut menunjukkan bahwa nilai TDS mengalami peningkatan setelah perlakuan fitoremediasi oleh tumbuhan Sagittaria lancifolia. Peningkatan yang terjadi disebabkan oleh adanya kenaikan bahan organik didalam media tanam, akibat banyaknya bagian tumbuhan yang mati seiring bertambahnya umur. Semakin tinggi konsentrasi deterjen maka semakin tinggi pula nilai TDS pada media tanam.

Perlakuan antara fitoremediasi, konsentrasi dan waktu detensi terhadap nilai TDS pada media tanam dapat dilihat pada Gambar 2. Rerata nilai TDS yang fluktuatif setiap harinya, selama 14 hari. Setelah dilakuan fitoremediasi, rerata nilai TDS mengalami kenaikan dibandingkan sebelum difitoremediasi (Gambar 2). 
Jurnal Tanah dan Sumberdaya Lahan Vol 7 No 1 : 143-148, 2020

e-ISSN:2549-9793, doi: 10.21776/ub.jts1.2020.007.1.18

Tabel 2. Rerata TDS pada berbagai konsentrasi deterjen dan waktu detensi 14 hari.

\begin{tabular}{|c|c|c|c|c|c|c|}
\hline \multirow[t]{2}{*}{ Hari ke- } & \multicolumn{3}{|c|}{ Kontrol (tanpa tumbuhan) $\mathrm{mg} \mathrm{L}^{-1}$} & \multicolumn{3}{|c|}{ Perlakuan (ada tumbuhan) $\mathrm{mg} \mathrm{L}^{-1}$} \\
\hline & $10 \mathrm{ppm}$ & $50 \mathrm{ppm}$ & $75 \mathrm{ppm}$ & $10 \mathrm{ppm}$ & $50 \mathrm{ppm}$ & $75 \mathrm{ppm}$ \\
\hline 1 & 165 & 184 & 189 & 182 & 188 & 193 \\
\hline 2 & 170 & 190 & 202 & 166 & 180 & 200 \\
\hline 3 & 169 & 189 & 192 & 164 & 187 & 219 \\
\hline 4 & 183 & 192 & 203 & 179 & 203 & 232 \\
\hline 5 & 177 & 195 & 198 & 173 & 201 & 233 \\
\hline 6 & 170 & 195 & 201 & 178 & 205 & 237 \\
\hline 7 & 173 & 197 & 202 & 188 & 214 & 242 \\
\hline 8 & 174 & 198 & 207 & 191 & 214 & 243 \\
\hline 9 & 178 & 203 & 206 & 195 & 220 & 252 \\
\hline 10 & 183 & 203 & 210 & 194 & 219 & 250 \\
\hline 11 & 177 & 199 & 210 & 195 & 223 & 255 \\
\hline 12 & 182 & 204 & 210 & 200 & 224 & 257 \\
\hline 13 & 174 & 199 & 208 & 194 & 222 & 252 \\
\hline 14 & 177 & 202 & 215 & 196 & 218 & 247 \\
\hline Rata-rata & 175 & 196 & 204 & 185 & 208 & 237 \\
\hline
\end{tabular}

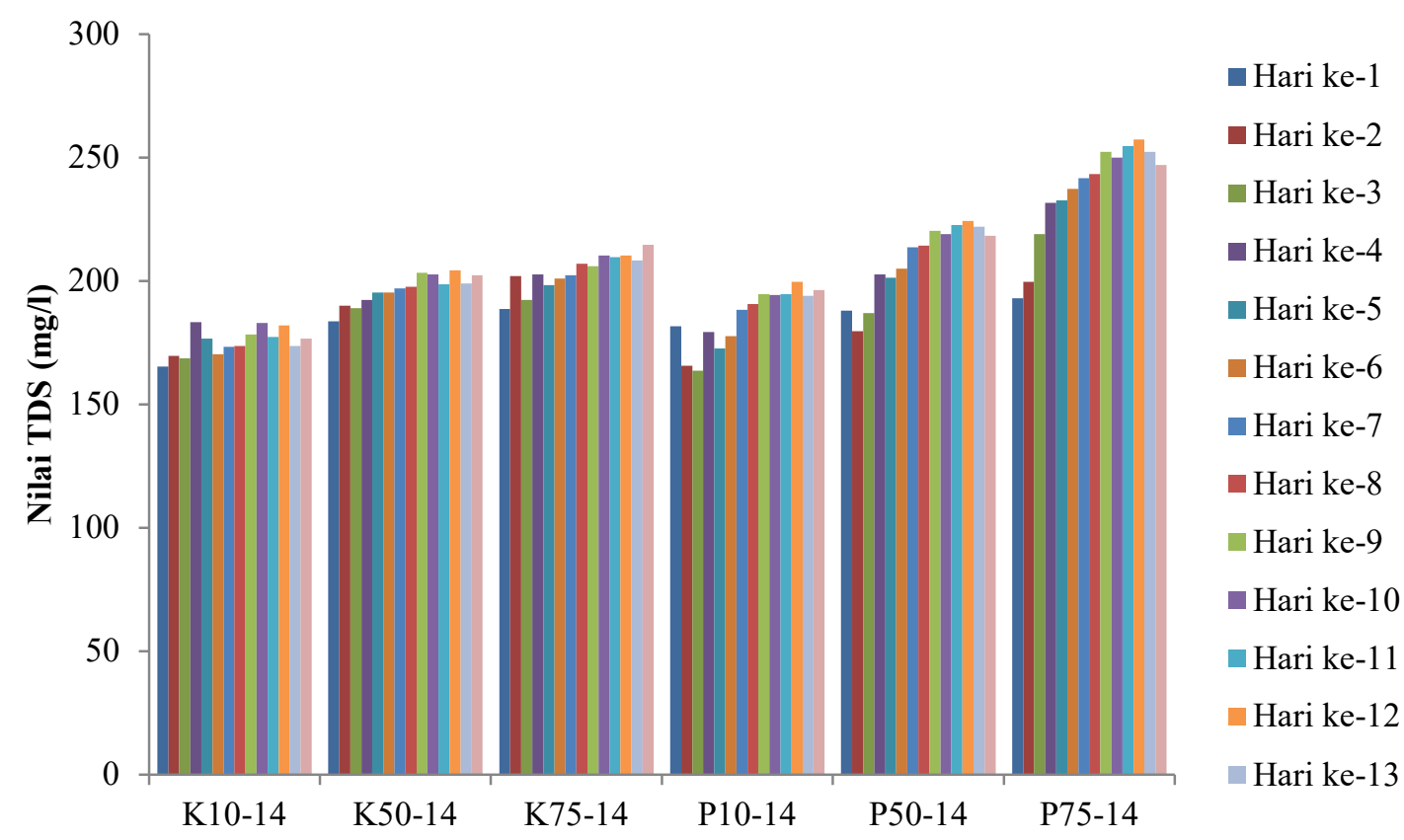

Gambar 2. Rerata TDS pada berbagai konsentrasi deterjen dan waktu detensi 14 hari. Keterangan:

K10-14: kontrol, 10 ppm, 14 hari K50-14: kontrol, 50 ppm, 14 hari K75-14: kontrol, 75 ppm, 14 hari
P10-14: perlakuan, $10 \mathrm{ppm}, 14$ hari P50-14: perlakuan, $50 \mathrm{ppm}, 14$ hari P75-14: perlakuan, 75 ppm, 14 hari
Hal ini sejalan dengan penelitian Prastiwi dan Irawanto (2019), yang mengungkapkan bahwa hasil pengamatan lapangan parameter TDS di kolam IV A dan IV B dengan adanya tumbuhan Sagittaria lancifolia menunjukkan bahwa nilai TDS cenderung fluktuatif selama 7 kali 
pengamatan. Pada penelitian Setiari et al. (2012) tingginya nilai TDS di suatu perairan bisa disebabkan oleh sisa-sisa bahan anorganik serta molekul yang disebabkan oleh sisa-sisa air buangan seperti deterjen, surfaktan yang larut dalam air dan molekul sabun.

\section{Kesimpulan}

Berdasarkan hasil penelitian yang telah dilakukan pada fitoremediasi larutan deterjen menggunakan tumbuhan Sagittaria lancifolia menunjukkan nilai TDS yang fluktuatif setiap harinya. Perlakuan terbaik ditunjukkan pada fitoremediasi (ada tumbuhan) konsentrasi 10 ppm dan waktu detensi 7 hari dengan rerata nilai TDS sebesar $174 \mathrm{mg} \mathrm{L}^{-1}$. Kondisi ini menunjukkan bahwa tumbuhan Sagittaria lancifolia mampu menurunkan nilai TDS pada media tanam. Namun, perlakuan fitoremediasi tidak semuanya menyebabkan penurunan TDS pada media tanam, beberapa diantaranya menunjukkan kenaikan seiring peningkatan konsentrasi deterjen dan lama waktu detensi.

\section{Ucapan Terima Kasih}

Penulis mengucapkan terima kasih kepada staff teknis KRP mas Pur dan mas Afif yang telah membantu dalam penelitian ini, Balai Konservasi Tumbuhan Kebun Raya Purwodadi - LIPI serta panitia Seminar Nasional Penelitian dan Pengabdian Masyarakat atas kesempatan yang telah diberikan.

\section{Daftar Pustaka}

Ahmad, J. and El-Dessouky, H. 2008. Design of a modified low cost treatment system for the recycling and a reuse of a laundry waste water. Resources, Conservation \& Recycling 52:973978.

Baroroh, F. dan Irawanto, R. 2016. Seleksi Tumbuhan Akuatik Berpotensi Dalam Fitoremediasi Air Limbah Domestik di Kebun Raya Purwodadi. Prosiding Seminar Nasional Biologi. Universitas Negeri Malang, Malang.

Febrianda, E., Harahap, S. dan Purwanto, E. 2018. Efektivitas penggunaan biofilter dengan proses anaerob, aerob, eceng gondok (Eichhornia crassipes) untuk menurunkan kadar TSS, TDS pada limbah cair laundry. Jurnal Online Mahasiswa (JOM) Bidang Perikanan dan Ilmu Kelautan 5(1):1-10.
Irawanto, R. 2016. Fitoremediasi Mengunakan Tumbuhan Akuatik Koleksi Kebun Raya Purwodadi.

Li, S., Gu, S., Liu, W., Han, H. and Zhang, Q. 2008. Water quality in relation to land use and land cover in the upper Han River Basin, China. Science Direct 75:216-222.

Prasetyo, H.D. dan Retnaningdyah, C. 2013. Peningkatan kualitas air irigasi akibat penanaman vegetasi riparian dari hidromakrofita lokal selama 50 hari. Jurnal Biotropika 1(4):149-153.

Prastiwi, E.A. dan Irawanto, R. 2019. Peran Tumbuhan Akuatik Sebagai Fitoremediasi Melalui Pemantauan Kualitas Air di Kebun Raya Purwodadi. Prosiding Seminar Nasional Biologi IP2B III 2019_ ISBN: 978.000: 1-6.

Safitri, M., Mukarlina dan Setyawati, T.R. 2019. Pemanfaatan Lemna minor L. dan Hydrilla verticillata (L.f.) Royle untuk memperbaiki kualitas air limbah laundry. Protobiont 8(1):39-44.

Setiari, M., Mahendra, M.S. dan Suyasa, W. 2012. Identifikasi sumber pencemar dan analisis kualitas air tukad yeh sungi di Kabupaten Tabanan dengan metode indeks pencemaran. Jurnal Ilmu Lingkungan 7(1):40 - 16.

Sudiro dan Agnes, T.A. 2013. Kajian efektifitas tanaman air Lemna minor dan Hydrilla verticillata dalam mereduksi BOD dan COD sebagai upaya perbaikan kualitas limbah cair industri tahu. Jurnal Spectra, Jurusan Teknik Lingkungan Institut Teknologi Nasional, Malang.

Suriawira, U. 2005. Mikrobiologi Dasar. Papas Sinar Sinanti, Jakarta. 